\title{
Biopharmaceutical Properties of Tubeimoside-1: A Cytotoxic Amphipathic Cyclic Bisdesmoside
}

Keisuke Oda, Tomomi Umakoshi, Nobuhiro Mori, Ryoji Kasai, and Teruo Murakami*

Laboratory of Biopharmaceutics and Pharmacokinetics, Faculty of Pharmaceutical Sciences, Hiroshima International University, 5-1-1 Hirokoshingai, Kure 737-0112, Japan

\begin{abstract}
Background: Biopharmaceutical properties of tubeimoside-1, a cytotoxic amphipathic cyclic bisdesmoside, were evaluated to search for the usefulness of tubeimoside- 1.

Methods: Using tubeimoside-1, the solubilizing activity to itraconazole, effect on oral absorption of itraconazole in rats, stability in aqueous solution and intestinal homogenate, cytotoxicity to Caco2 cells, and membrane permeability across rat intestine and Caco- 2 cell monolayers were evaluated. Concentrations of tubeimoside-1 were analyzed by LC-MS.

Results: The solubility of itraconazole was $38.0 \mu \mathrm{g} / \mathrm{mL}$ in water containing $2.5 \%$ propylene glycol. Tubeimoside- 1 and hydroxypropyl- $\beta$-cyclodextrin at a concentration of $10 \%$ increased itraconazole solubility to $6.5 \mathrm{mg} / \mathrm{mL}$ and $0.72 \mathrm{mg} / \mathrm{mL}$, respectively. In rats, coadministration of tubeimoside- 1 (10\%) significantly increased the oral absorption of itraconazole, however, the enhancing effect was almost half of hydroxypropyl- $\beta$-cyclodextrin (10\%). Tubeimoside- 1 was gradually degraded under acidic condition and in S9 fraction of intestinal mucosal homogenates. The cytotoxicity of tubeimoside-1 was observed in Caco- 2 cells. The membrane permeability of tubeimoside- 1 was almost negligible in rat intestine in situ and Caco-2 cell monolayers in vitro.
\end{abstract}

Conclusions: Greater solubilizing activity and biodegradability of tubeimoside-1, in addition to cytotoxicity, were observed. Further study is necessary to search for the usefulness of tubeimoside- 1 as a strong solubilizer by forming inclusion complex with lipophilic compounds.

\section{Publication History:}

Received: December 12, 2016 Accepted: March 06, 2017

Published: March 08, 2017

\section{Keywords:}

Hydroxypropyl- $\beta$-cyclodextrin, Itraconazole, Permeability, Solubilizing activity, Stability, Tubeimoside-1

\section{Introduction}

Steamed and dried tubers of Bolbostemma paniculatum (MAXIM.) FRANQUET (Cucurbitaceae), named as "Tu Bei Mu", has been used as an anti-inflammatory agent for mastitis and an antidote for snake skin in China, and tubeimoside-1 (T-1), a cyclic bisdesmoside, was isolated as one of active ingredients from the methanolic extract of the tubers (Figure 1) [1,2]. T-1 suppresses cell growth and induces cell apoptosis of various cancer cells in vitro [3,4]. T-1, an amphiphilic compound having a relatively lipophilic exterior surface and nonpolar interior cavity, increased the solubility of poorly water soluble compounds such as Saponin A, Yellow OB and $\alpha$-tocopherol [1,5]. In the present study, using $\mathrm{T}-1$, the solubilizing activity to itraconazole (ITZ), effect on oral absorption of ITZ in rats, stability in aqueous buffer and intestinal homogenate, cytotoxicity to Caco-2 cells, and membrane permeability across rat small intestine and Caco- 2 cell monolayers were examined to understand the biopharmaceutical properties of unique amphipathic inclusion compound and to search for the usefulness of T-1. Itraconazole (ITZ) and hydroxypropyl- $\beta$ cyclodextrine $(\mathrm{HP} \beta \mathrm{CD})$ were used as a poor water-soluble compound and a potent inclusion compound, respectively [6]. As clinically available formulation of ITZ, ITZ $(10 \mathrm{mg} / \mathrm{mL})$ is solubilized by $40 \% \mathrm{HP} \beta \mathrm{CD}$ to form a molecular inclusion complex (SPORANOX ${ }^{\circ}$ (itraconazole) Oral Solution, Janssen Pharmaceutica N.V. Beerse, Belgium).

\section{Material and Methods}

\section{Materials}

ITZ and HP $\beta C D$ were purchased from Sigma Chemical Co. Ltd (St Louis, USA). Cell culture medium and reagents were from Gibco Laboratories (Life Technologies Inc., Grand Island, NY). All other chemicals used were of the highest purity available.

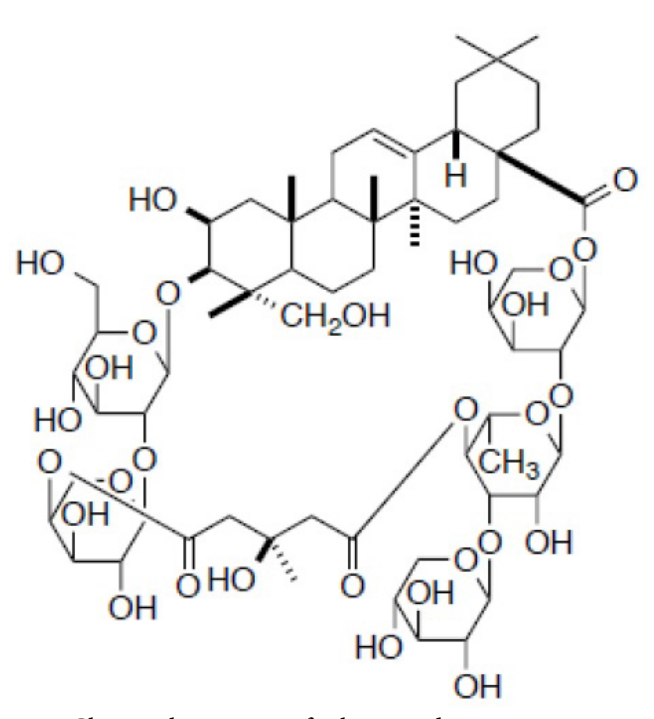

Figure 1: Chemical structure of tubeimoside 1.

"Corresponding Author: Prof. Teruo Murakami, Laboratory of Biopharmaceutics and Pharmacokinetics, Faculty of Pharmaceutical Sciences, Hiroshima International University, 5-1-1 Hiro-koshingai, Kure, Hiroshima 737-0112, Japan, Tel: +81-823-73-8994; E-mail: t-muraka@ps.hirokoku-u.ac.jp

Citation: Oda K, Umakoshi T, Mori N, Kasai R, Murakami T (2017) Biopharmaceutical Properties of Tubeimoside-1: A Cytotoxic Amphipathic Cyclic Bisdesmoside. Int J Clin Pharmacol Pharmacother 2: 126. doi: https://doi. org/10.15344/2017/2456-3501/126

Copyright: @ 2017 Oda et al. This is an open-access article distributed under the terms of the Creative Commons Attribution License, which permits unrestricted use, distribution, and reproduction in any medium, provided the original author and source are credited. 
Citation: Oda K, Umakoshi T, Mori N, Kasai R, Murakami T (2017) Biopharmaceutical Properties of Tubeimoside-1: A Cytotoxic Amphipathic Cyclic Bisdesmoside. Int J Clin Pharmacol Pharmacother 2: 126. doi: https://doi.org/10.15344/2017/2456-3501/126

Page 2 of 6

\section{Extraction of T-1}

T-1 was extracted from traditional Chinese herbal medicine Bolbostemma paniculatum (Maxim.) Franquet (Cucurbitaceae) using a methanol extract of the tubers in the same manner as reported previously $[1,2]$.

\section{Effects of T-1 and HP $\beta$ CD on ITZ solubility}

Excess amount of ITZ (approximately $12 \mathrm{mg}$ ) was dissolved in a mixture of propylene glycol $(17.5 \mu \mathrm{L})$ and 10 mole/ $\mathrm{L} \mathrm{HCl}(4.375 \mu \mathrm{L})$ pre-warmed at $40-50^{\circ} \mathrm{C}$, according to the method reported previously [7]. T- 1 or $\mathrm{HP} \beta \mathrm{CD}$ saline solution $(674.45 \mu \mathrm{L})$ containing 10 mole/L $\mathrm{NaOH}$ solution $(3.675 \mu \mathrm{L})$ were added at room temperature. The final concentration of propylene glycol and $\mathrm{pH}$ were $2.5 \%$ and approximately neutral, respectively. The concentrations of T-1 and $\mathrm{HP} \beta C D$ were adjusted at $0,2,10$ or $40 \%$. For comparison, non-ionic polyethoxylated detergent, Cremophor EL (Sigma-Aldrich Japan. Tokyo), was also used at a concentration of $10 \%$. Prior to the analysis, the final mixture containing undissolved ITZ was passed through a 0.45 - $\mathrm{mm}$ syringe filter.

\section{Effects of T-1 and HP $\beta C D$ on oral absorption of ITZ in rats}

Male Sprague-Dawley rats aged 7-9 weeks old were used. The protocol of the experiments was reviewed and approved in advance and experiments with animals were performed in accordance with the Guide for Animal Experimentation from the Committee of Research Facilities for Laboratory Animal Sciences, Hiroshima International University, which is in accordance with the Guidelines for Proper Conduct of Animal Experiments from the Science Council of Japan. The license number of this animal study was AE15-003. As a control, ITZ was suspended in saline $(10 \mathrm{mg} / \mathrm{mL})$ containing $2.5 \%$ propylene glycol. T- 1 or HP $\beta C D$ was added to the saline suspension of ITZ at a concentration of $10 \%$, in the same manner as described above. One night fasted rats received ITZ suspension by stomach intubation at a dose of ITZ $20 \mathrm{mg} / 2 \mathrm{~mL} / \mathrm{kg}$. Blood ( $0.25 \mathrm{~mL}$ each) was collected from jugular vein periodically under light anesthesia with diethylether and centrifuged to obtain plasma.

\section{Stability study of T-1}

The stability of T-1 in pH 7.4 phosphate buffered saline (PBS: $137 \mathrm{mM} \mathrm{NaCl}, 3 \mathrm{mM} \mathrm{KCl}, 8 \mathrm{mM} \mathrm{Na}_{2} \mathrm{HPO}_{4}$ and $1.5 \mathrm{mM} \mathrm{KH}_{2} \mathrm{PO}_{4}$ ) supplemented with $1 \mathrm{mM} \mathrm{CaCl}_{2}, 0.5 \mathrm{mM} \mathrm{MgCl}_{2}$ and $5 \mathrm{mM}$ glucose (PBS-G), pH $0.7 \mathrm{HCl}$ solution and $\mathrm{S} 9$ fraction of rat intestinal mucosa homogenates was determined at $37^{\circ} \mathrm{C}$. The $\mathrm{S} 9$ fraction was prepared by centrifuging $10 \%$ mucosa homogenate in $\mathrm{pH} 7.4$ $10 \mathrm{mM}$ HEPES-NaOH buffer containing $150 \mathrm{mM} \mathrm{KCl}$ and $1 \mathrm{mM}$ phenylmethanesulfonyl fluoride (PMSF) at 9,000 x g for $20 \mathrm{~min}$ at $4^{\circ} \mathrm{C}$. Concentrations of T- 1 and protein in $\mathrm{S} 9$ fraction were adjusted at $1 \mathrm{mg} / \mathrm{mL}$ and $100 \mu \mathrm{g} / \mathrm{mL}$, respectively, and the solution was incubated at $37^{\circ} \mathrm{C}$. The reaction was stopped by adding excess amount of acetonitrile and cooling to $4^{\circ} \mathrm{C}$.

\section{Cytotoxicity of T-1 to Caco-2 cells}

The viability of Caco- 2 cells after exposure to T- 1 was assessed using WST-1 (2-(4-Iodophenyl)-3- (4-nitrophenyl)-5-(2,4-disulfophenyl)$2 \mathrm{H}$-tetrazolium, monosodium salt, a cell proliferation reagent) according to the manufacture's protocol (Dojindo, Kumamoto, Japan). Briefly, Caco-2 cells cultured onto 96-well plates for 21 days were washed with $\mathrm{pH} 7.4 \mathrm{PBS}(100 \mu \mathrm{L})$ and treated with $100 \mu \mathrm{L}$ of
T-1 solution $(0.1-1,000 \mu \mathrm{M})$ dissolved in serum free Dulbecco's Modified Eagle Medium (DMEM). After 1 or 24 h-incubation at $37^{\circ} \mathrm{C}, \mathrm{T}-1$ solution was discarded and WST-1 reaction mixture $(100$ $\mu \mathrm{L})$ containing WST-1 and 1-methoxy phenazinium methylsulfate (1-methoxy PMS) was added. After 60 min-incubation, the UV absorbance at $450 \mathrm{~nm}$ was measured with a microplate reader (SpectraMax Plus 384, Molecular Devices Japan). The 50\% inhibitory concentration of cell growth $\left(\mathrm{IC}_{50}\right)$ was calculated by curve fitting.

\section{Membrane permeability of T-1 across intestinal loop in situ and Caco- 2 cell monolayers in vitro}

Bile duct of anaesthetized rats was ligated and the intestinal lumen was washed with a sufficient amount of saline prewarmed at $37^{\circ} \mathrm{C}$. Three intestinal loops of $10 \mathrm{~cm}$-long each were made by ligating both ends of the intestinal loop at proximal (a segment from $5 \mathrm{~cm}$ below the bile duct opening), middle, and distal small intestine (a segment from $5 \mathrm{~cm}$ above the ileocecum). T- $1(0.5 \mathrm{mg} / \mathrm{mL})$ was dissolved in $\mathrm{pH}$ 7.4 PBS-G. T-1 solution ( $1 \mathrm{~mL}$ ) was administered into the loop, and the luminal fluid was recovered $1 \mathrm{~h}$ after administration by washing the intestinal lumen with sufficient amounts of PBS-G. The collected luminal fluid was deproteinized with acetonitrile.

Caco-2 cell monolayers cultured in 12 -well Transwell ${ }^{\bullet}$ chamber (Costar, Cambridge, MA) were used after monitoring the transepithelial electric resistance (TEER) with a Millicell electrical resistance system testing device (Millipore, Bedford, MA, USA). Monolayers with TEER of more than $500 \Omega \cdot \mathrm{cm}^{2}$ were used. T-1 (10 or $30 \cdot \mu \mathrm{M})$ was dissolved in $\mathrm{pH} 6.0$ PBS-G. The solution $(0.5 \mathrm{~mL})$ was placed on the apical side, and the other side was filled with $1.5 \mathrm{~mL}$ of pH 7.4 PBS-G. The Transwell ${ }^{\circ}$ chamber was incubated at $37^{\circ} \mathrm{C}$, and the transport medium $(100 \mu \mathrm{L})$ in the basolateral side was sampled periodically to determine T-1 concentrations. Fresh transport medium was refilled each time.

\section{Analysis}

Concentrations of ITZ were determined by HPLC. Plasma samples were deproteinized with an equal volume of acetonitril. The column used was YMC-Triart C18 (YMC Co. Ltd., Kyoto, Japan) and the mobile phase was a mixture of acetonitrile and $1 \%$ acetic acid $(55: 45 \mathrm{v} / \mathrm{v})$. The flow rate was $1 \mathrm{~mL} / \mathrm{min}$, and detection of ITZ was made at UV $260 \mathrm{~nm}$. Concentration of protein was measured by Bradford method using bovine serum albumin as the standard [8]. Concentrations of T-1 in various samples were measured by using liquid chromatography/mass spectrometry (LC-MS, Shimadzu LCMS8040, Japan) after deproteinization with acetonitrile. CAPCELL PAK C18 MG III S3 (50 mm, 2.0 mm I.D., Shiseido, Japan) was used as a column and eluted with a mixture of $0.25 \mathrm{mM}$ sodium acetate (solution $\mathrm{A}$ ) and acetonitrile (solution $\mathrm{B}$ ) using a following linear gradient: $20 \%$ to $70 \%$ of B for $4 \mathrm{~min}, 70 \%$ of B for $4-4.5 \mathrm{~min}$, and $20 \%$ of $B$ for $4.5-8 \mathrm{~min}$. The temperature of the sample cooler was set to $4^{\circ} \mathrm{C}$ and the flow rate was $0.3 \mathrm{~mL} / \mathrm{min}$. Selected ion monitoring (SIM) was performed with the $\mathrm{m} / \mathrm{z}$ 1341.9. The calibration curve showed a good linear correlation over the concentration range from 0.025 to $10 \mu \mathrm{M}(\mathrm{r}=>0.99)$.

\section{Statistical analysis}

Data were presented as the mean \pm SE. Statistical analysis was performed by Student's t-test, or by one-way analysis of variance followed by the Turkey-Kramer's Test for multiple comparisons. A difference of $\mathrm{P}<0.05$ was considered statistically significant. 
Citation: Oda K, Umakoshi T, Mori N, Kasai R, Murakami T (2017) Biopharmaceutical Properties of Tubeimoside-1: A Cytotoxic Amphipathic Cyclic Bisdesmoside. Int J Clin Pharmacol Pharmacother 2: 126. doi: https://doi.org/10.15344/2017/2456-3501/126

Page 3 of 6

\section{Results}

\section{Effects of T-1 and HP $\beta$ CD on ITZ solubility}

Effects of T-1 and HP $\beta$ CD on ITZ solubility were evaluated, in which excess amount of ITZ was dissolved in a small volume of a mixture of propylene glycol and $\mathrm{HCl}$, the solution was mixed with 0 , 2,10 and/or $40 \% \mathrm{~T}-1$ or HP $\beta$ CD saline solution containing a small amount of $\mathrm{NaOH}$ (Figure 2). The final concentration of propylene glycol was $2.5 \%$ and $\mathrm{pH}$ was neutral. The solubility of ITZ itself was $38.0 \mu \mathrm{g} / \mathrm{mL}$. In the presence of $10 \% \mathrm{~T}-1$, the solubility of ITZ increased to $6.47 \pm 0.16 \mathrm{mg} / \mathrm{mL}$, and it was about 9 -fold higher than that of $10 \%$ $\mathrm{HP} \beta \mathrm{CD}(0.75 \pm 0.20 \mathrm{mg} / \mathrm{mL})$. At $40 \% \mathrm{HP} \beta \mathrm{CD}$, the solubility of ITZ reached to approximately $10.13 \pm 0.14 \mathrm{mg} / \mathrm{mL}$. Cremophor EL, a nonionic polyethoxylated detergent, at a concentration of $10 \%$ increased ITZ solubility to $56.5 \mu \mathrm{g} / \mathrm{mL}$, twice of ITZ alone.

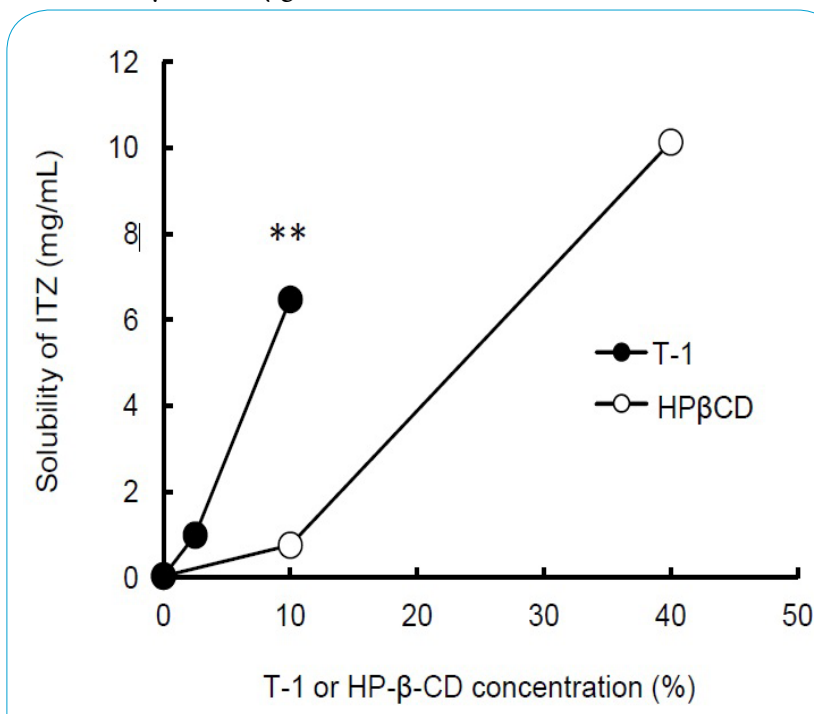

Figure 2: Solubility of itoraconazole (ITZ) in the presence of T-1 or $\mathrm{HP} \beta \mathrm{CD}$ at room temperature. Excess amount of ITZ (approximately 12 $\mathrm{mg}$ ) was dissolved in a small volume of a mixture of propylene glycol and $\mathrm{HCl}$, and the solution was mixted with saline solution of T-1 or $\mathrm{HP} \beta \mathrm{CD}$ containing a small amount of $\mathrm{NaOH}$. The final concentration of propylene glycol in the mixture was $10 \%$ and $\mathrm{pH}$ was approximately neutral, respectively. Each value represents the mean \pm SE of $4-12$ determinants. ${ }^{*} \mathrm{P}<0.01$, significantly different from the value of $10 \%$ HP $\beta C D$.

\section{Effects of T-1 and HP $\beta C D$ on oral absorption of ITZ in rats}

Three different formulations, that is., ITZ saline suspension containing dissolved ITZ $(38.0 \mu \mathrm{g} / \mathrm{mL})$ and undissolved ITZ $(9.962$ $\mathrm{mg} / \mathrm{mL}$ ), ITZ saline suspension contaning $10 \% \mathrm{~T}-1$ (ITZ/10\%T-1 suspension containing dissolved ITZ $(38.0 \mu \mathrm{g} / \mathrm{mL})$, undissolved ITZ $(3.53 \mathrm{mg} / \mathrm{mL})$, and $6.432 \mathrm{mg} / \mathrm{mL}$ ITZ/10\%T-1 inclusion complex), and ITZ saline suspension containing $10 \% \mathrm{HP} \beta \mathrm{CD}$ (ITZ/10\%HP $\beta \mathrm{CD}$ suspension containing dissolved ITZ $(38.0 \mu \mathrm{g} / \mathrm{mL})$, undissolved ITZ (9.25 mg), and $0.712 \mathrm{mg} / \mathrm{mL}$ ITZ/10\%T-1 inclusion complex), were administered orally at a dose of $20 \mathrm{mg} / 2 \mathrm{~mL} / \mathrm{kg}$ of ITZ (Figure 3). The intestinal absorption of ITZ given as ITZ/10\%T- 1 suspension was higher than that of ITZ saline suspension as follows: the peak plasma concentration $(\mathrm{Cmax})$ and area under the concentration-time curve from 0 to $4 \mathrm{~h}\left(\mathrm{AUC}_{0-4}\right)$ of ITZ were $0.14 \pm 0.03 \mu \mathrm{g} / \mathrm{mL}($ mean $\pm \mathrm{SE}, \mathrm{n}=$ $3-4)$ and $14.6 \pm 3.72 \mu \mathrm{g} \cdot \mathrm{min} / \mathrm{mL}$ after saline suspension, and $0.31 \pm 0.04$ and $46.8 \pm 12.0$ after ITZ/10\%T-1 suspension, respectively. However, Cmax and $\mathrm{AUC}_{0-4}$ of ITZ given as ITZ/10\%HP $\beta C D$ suspension were further increased as follows: $0.78 \pm 0.28 \mu \mathrm{g} / \mathrm{mL}$ and $114 \pm 30.2 \mu \mathrm{g} \bullet \mathrm{min} /$ $\mathrm{mL}$, respectively. The $\mathrm{AUC}_{0-4}$ of ITZ/10\%HP $\beta \mathrm{CD}$ suspension was significantly higher than that of the saline suspension $(\mathrm{P}<0.05)$.

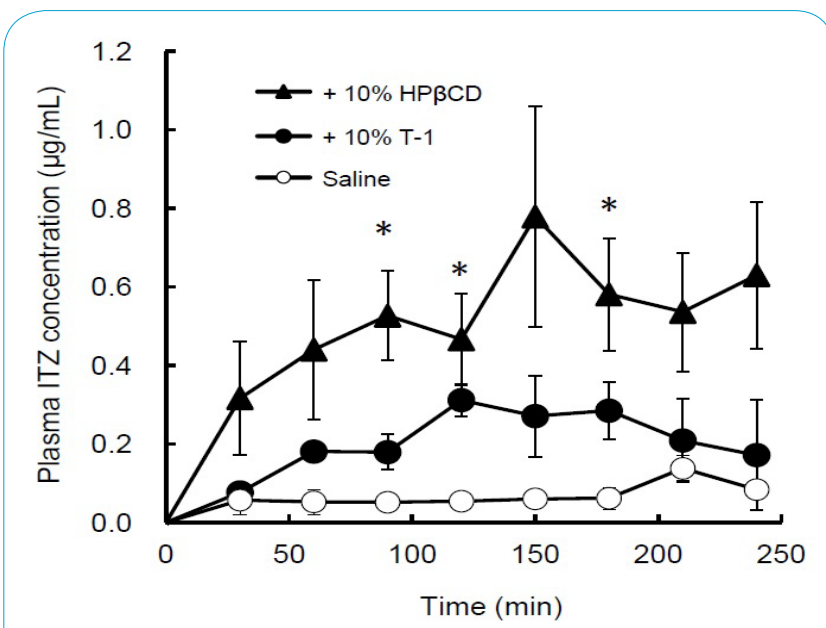

Figure 3: Concentrations of itraconazole (ITZ) after oral administration of ITZ, ITZ/10\%T- 1 , and ITZ/10\% HP $\beta$ CD saline suspension a dose of $20 \mathrm{mg} \mathrm{ITZ} / 2 \mathrm{~mL} / \mathrm{kg}$ in rats. Each value represents the mean $\pm \mathrm{SE}$ of three - four experiments. ${ }^{\star} P<0.05$, significantly different from the value of saline suspension.

\section{Recovery of T-1 from intestinal loop in situ}

T-1 solution $(500 \mu \mathrm{g} / \mathrm{mL})$ was administered into $10 \mathrm{~cm}$ long intestinal loops, and the remaining amount of T-1 in the loop $1 \mathrm{~h}$ after administration was determined (Figure 4). The recovered amounts of $\mathrm{T}-1$ were comparable among three different regions. In these experiments, T-1 was not detected in blood circulation, suggesting the disappearance of $\mathrm{T}-1$ from the loop was not due to the intestinal absorption of T-1.

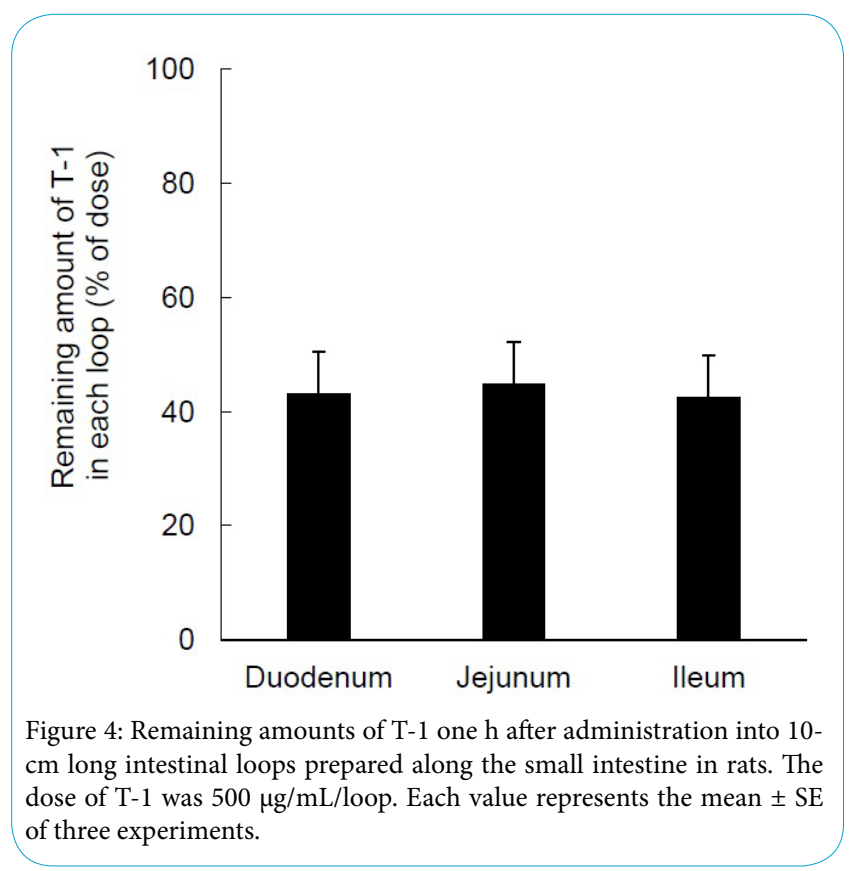

\section{Discussion}

Biopharmaceutical properties of T-1 were evaluated to search for the usefulness of tubeimoside-1, as an unique amphipathic 
Citation: Oda K, Umakoshi T, Mori N, Kasai R, Murakami T (2017) Biopharmaceutical Properties of Tubeimoside-1: A Cytotoxic Amphipathic Cyclic Bisdesmoside. Int J Clin Pharmacol Pharmacother 2: 126. doi: https://doi.org/10.15344/2017/2456-3501/126

cyclic bisdesmoside. The in vitro solubilizing activity of T-1 has been reported already using several poor water soluble compounds such as Saponin A, Yellow OB, and dl- $\alpha$-tocopherol [2,5]. However, the efficacy of solubilizing effect of T-1 in oral absorption of poor water soluble compounds in vivo was not yet examined. To compare the solubilizing activity of T-1, HP $\beta C D$ was used as a reference inclusion compound. HP $\beta C D$ has high water solubility (more than 60\%), possesses high solubilizing activity against variety of poorly water soluble compounds, and is used as a pharmaceutical solubilizer of drugs including ITZ $[9,10]$. The effect of Cremophor EL, a non-ionic polyethoxylated detergent, on ITZ solubility was also examined for comparison, since T-1 is reported to have a surface tension-reducing activity. The critical micelle concentration $(\mathrm{cmc})$ of T-1 is reported to be $0.001 \%(7 \mu \mathrm{M})$, at which the surface tension of $\mathrm{T}-1$ solution was $54 \mathrm{dyn} / \mathrm{cm}$ [5]. ITZ, a triazole antifungal agent, is a weak basic compound with a pKa value of 3.70 . The solubility of ITZ, categorized as a biopharmaceutical classification system (BCS) class II compound with low solubility and high permeability [11], is reported to be 1-4 ng/ $\mathrm{mL}$ in water and $4-6 \mu \mathrm{g} / \mathrm{mL}$ in $\mathrm{pH} 1.2(0.1 \mathrm{~N} \mathrm{HCl})$. The dose number $\left(\mathrm{D}_{0}=\right.$ (maximum dose strength $\left./ 250 \mathrm{~mL}\right) /$ minimum solubility) of ITZ was estimated to be 800,000 , by assuming that the minimum water solubility of ITZ is $1 \mathrm{ng} / \mathrm{mL}$ and maximum dose strength is $200 \mathrm{mg}$ each in human. The oral absorption of ITZ is known to be scattered among patients and doses possibly due to the low solubility, and intake of food increases oral bioavailability of ITZ due to the solubilization by bile acids $[12,13]$. The average value of plasma Cmax of ITZ given orally $(200 \mathrm{mg}$ ) after fasting was about $59 \%$ that after the standard meal in healthy volunteers $[13,14]$. In contrast, ITZ oral solution containing $40 \% \mathrm{HP} \beta \mathrm{CD}$ exhibited greater oral bioavailability than ITZ capsule in the fasted state than in the nonfasted state in healthy volunteers $[12,15]$. Gastric $\mathrm{pH}$ alterations due to the coadministration of proton pump inhibitors (PPIs) or acidic beverages such as CocaCola are also reported to significantly decrease or increase the bioavailability of ITZ, by modulating the solubility of ITZ in the stomach $[16,17]$. It is reported that ITZ absorption is promoted by low stomach $\mathrm{pH}$, long gastric retention time and a high fat content of the coadministered meal [18]. The dose-dependent oral bioavailability of ITZ due to the high intestinal first-pass effect in rats is also reported as follows: bioavailability of ITZ was $34.9 \%$ at a dose of $10 \mathrm{mg} / \mathrm{kg}$; $63.0 \%$ at $30 \mathrm{mg} / \mathrm{kg}$, and $85.7 \%$ at $50 \mathrm{mg} / \mathrm{kg}$, in which the hepatic firstpass effect was relatively low $[19,20]$.

In the present study, ITZ was dissolved in a small volume of a mixture of propylene glycol and $\mathrm{HCl}$, and mixed with $\mathrm{T}-1$ or $\mathrm{HP} \beta \mathrm{CD}$ solution. The final concentration of propylene glycol was $2.5 \%$ and $\mathrm{pH}$ of the final mixture was adjusted to approximately neutral. The solubility of ITZ alone was $38 \mu \mathrm{g} / \mathrm{mL}$, and $10 \% \mathrm{~T}-1$ increased the ITZ solubility by 170 -fold of ITZ alone. The high solubility of ITZ in the present study $(38.0 \mu \mathrm{g} / \mathrm{mL})$ compared to reported value $(1-4 \mathrm{ng} /$ $\mathrm{mL}$ ) would be due to the presence of propylene glycol (2.5\%). The solubilizing activity of T-1 at a concentration of $10 \%$ was nine-fold greater than that of $\mathrm{HP} \beta \mathrm{CD}$ (Fig. 2). The molar ratio of ITZ (solubility $9.22 \mathrm{mmole} / \mathrm{L})$ against $10 \% \mathrm{~T}-1$ (75.8 mmole/L) was approximately 0.122 , implying that approximately eight $\mathrm{T}-1$ molecules interact with one ITZ molecule. The solubilizing activity of T-1 was not considered to be derived from the surface tension reducing activity, but due to the formation of inclusion complex between T-1 and ITZ, since Cromophor EL (10\%), a surfactant, increased ITZ solubility only twice. The absorption enhancing effect of T-1 was examined in rats using ITZ. Though ITZ/10\%T-1 suspension increased the $\mathrm{AUC}_{0-4}$ of ITZ three-fold of ITZ saline suspension, ITZ/10\% HP $\beta C D$ suspension further increased the ITZ absorption, more than twice of ITZ/10\%T-1 suspension (Figure 3). The reason of the low absorption enhancing effect of T-1 compared to $\mathrm{HP} \beta \mathrm{CD}$, irrespective of the greater solubilizing activity, would be accounted for by the instability of T-1 resulting in the degradation of the inclusion complex between T- 1 and ITZ. In loop study, approximately $60 \%$ of T- 1 was disappeared from the loop within $1 \mathrm{~h}$ after dosing, but it was due to the degradation of T-1 in tissues. Also, no membrane permeation of T-1 itself was observed (Figure 4 and Figure 5). In contrast, if the ITZ/10\%T-1 inclusion complex was stable in gastrointestinal tract and the solubility of ITZ increased to the level of intact ITZ/10\%T-1 inclusion complex, the dose number of ITZ may correspond to 0.12 by adopting $6.47 \mathrm{mg} / \mathrm{mL}$ as the minimum solubility of ITZ as well as ITZ/10\%T-1 inclusion complex. The low dose number may imply that the intact ITZ/10\%T-1 inclusion complex is a high solubility compound with low membrane permeability like BCS Class III compounds. In general, however, the intestinal absorption of compounds having large molecular weights is not expected much, because of the low diffusion coefficients in passing the unstirred water layer (USWL) in the intestine. Most drug/CD inclusion complexes would release the lipophilic drug in the gastrointestinal tract and increase the intestinal absorption of the lipophilic drug. On the other hand, CD molecules that released drug molecules are retained in the intestinal tract. CDs are bulky and hydrophilic compounds and therefore basically poorly absorbed. It is summarized that the oral bioavailabilities of $\alpha C D, \beta C D$, $\gamma \mathrm{CD}$, and $\mathrm{HP} \beta \mathrm{CD}$ in rats were $2-3 \%, 0 \%$, less than $0.1 \%$, and less than $3 \%$, respectively [21]. It is also reported that the oral bioavailability of $\mathrm{HP} \beta C D$ in the majority of children patients was less than $1 \%$ [22]. It will be important to study further about the releasing mechanism of drug from drug/CDs inclusion complex in the intestinal tract, the releasing timing of drug (before or after diffusion of USWL), the fate of CD molecules after releasing drug molecules, and so on.

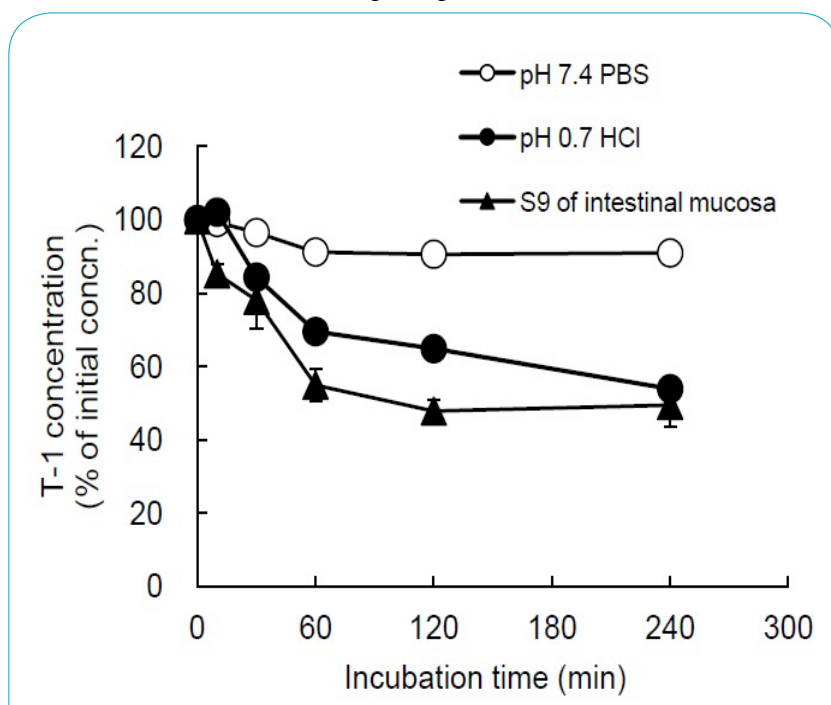

Figure 5: Stability of T-1 in pH 7.4 PBS, pH $0.7 \mathrm{HCl}$, and S9 fraction of rat intestinal mucosal homogenate at $37^{\circ} \mathrm{C}$. The value of $\mathrm{S} 9$ fraction represents the mean \pm SE of three experiments.

$\mathrm{T}-1$ is known to have anti-inflammatory, anti-tumor, and antitumorigenic activities [4,23-26], indicating that $\mathrm{T}-1$ is a cytotoxic compound. A potent cytotoxicity of T-1 was also observed in Caco2 cells (Figure 6). Also, the membrane permeability of T-1 across Caco-2 cell monolayers was not detected at a concentration of 10 $\mu \mathrm{M}$, but T-1 gradually permeated Caco- 2 cell monolayers with time at a concentration of $30 \mu \mathrm{M}$, possibly due to the cytotoxicity of T-1. 
Citation: Oda K, Umakoshi T, Mori N, Kasai R, Murakami T (2017) Biopharmaceutical Properties of Tubeimoside-1: A Cytotoxic Amphipathic Cyclic Bisdesmoside. Int J Clin Pharmacol Pharmacother 2: 126. doi: https://doi.org/10.15344/2017/2456-3501/126

Collectively, T-1 was not found to be suitable as a safe solubilizer of low water soluble compounds in enhancing the oral bioavailability in vivo. Instead, T-1 having an anticancer activity may be useful as a drug carrier of other lipophilic anticancer drugs, though some appropriate delivery system such as liposomes for T-1/anticancer agent inclusion complex is necessary.

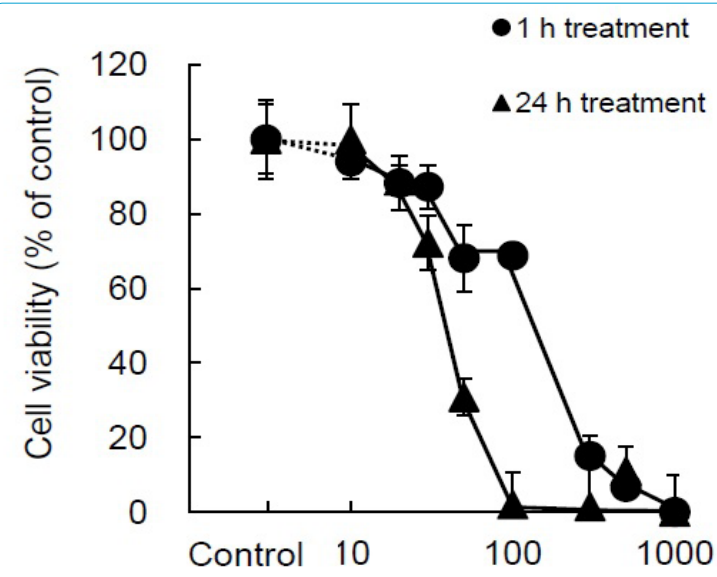

$\mathrm{T}-1$ concentration $(\mu \mathrm{M})$

Figure 6: Cytotoxicity of T-1 against Caco-2 cells. Incubation was carried out for $1 \mathrm{~h}$ or $24 \mathrm{~h}$ at $37^{\circ} \mathrm{C}$. Each value represents the mean $\pm \mathrm{SE}$ of three experiments.

\section{Conclusion}

Greater solubilizing activity and biodegradability of T-1, in addition to cytotoxicity, were observed. Further study is necessary to search for the usefulness of T-1 as a strong solubilizer by forming inclusion complex with lipophilic compounds.

\section{Competing Interests}

The authors declare that they have no competing interests.

\section{Author Contributions}

Oda K. designed experimental protocol and performed most of in vitro and animal experiments.

Umakoshi T. helped Dr. Oda with animal experiments and in vitro stability study.

Mori N. cultured and performed experiments using cells.

Kasai R. extracted tubeimoside- 1 from $\mathrm{Tu}$ Bei $\mathrm{Mu}$, and discussed regarding chemical properties.

Murakami T interpreted data and summarized it as a manuscript.

\section{Funding}

This research was financially supported by MEXT KAKENHI Grant Number JP20136055 in Japan.

\section{References}

1. Kasai R, Miyakoshi M, Matsumoto K, Nie RL, Zhou J, et al. (1986) Tubeimoside I, a new cyclic bisdesmoside from Chinese cucurbitaceous folk medicine "tu bei mu", a tuber of Bolbostemma paniculatum. Chem Pharm Bull (Tokyo) 34: 3974-3977.

2. Kasai R, Miyakoshi M, Matsumoto K, Nie RL, Zhou J, et al. (1988) Saponins from Bolbostemma Paniculatum: cyclic bisdesmosides, tubeimosides II and III. Phytochemistry 27: 1439-46.
3. Lin Y, Xie G, Xia J, Su D, Liu J, Et al. (2016) TBMS1 exerts its cytotoxicity in $\mathrm{NCl}-\mathrm{H} 460$ lung cancer cells through nucleolar stress-induced p53/MDM2dependent mechanism, a quantitative proteomics study. Biochim Biophys 1864: 204-210.

4. Yang JB, Khan M, He YY, Yao M, Li YM, et al. (2016) Tubeimoside-1 induces oxidative stress-mediated apoptosis and G0/G1 phase arrest in human prostate carcinoma cells in vitro. Acta Pharmacol Sin 37: 950-962.

5. Miyakoshi M, Kasai R, Nishioka M, Ochiai H, Tanaka O (1990) [Solubilizing effect and inclusion reaction of cyclic bisdesmosides from tubers of Bolbostemma paniculatum]. Yakugaku Zasshi 110: 943-949.

6. Brewster ME, Vandecruys R, Peeters J, Neeskens P, Verreck G, et al. (2008) Comparative interaction of 2-hydroxypropyl-beta-cyclodextrin and sulfobutylether-beta-cyclodextrin with itraconazole: phase-solubility behavior and stabilization of supersaturated drug solutions. Eur J Pharm Sci 34: 94-103.

7. Hostetler JS, Hanson LH, Stevens DA (1992) Effect of cyclodextrin on the pharmacology of antifungal oral azoles. Antimicrob Agents Chemother 36: 477-480.

8. Bradford MM (1976) A rapid and sensitive method for the quantitation of microgram quantities of protein utilizing the principle of protein-dye binding. Anal Biochem 72: 248-254.

9. Loftsson T, Hreinsdóttir D, Másson M (2005) Evaluation of cyclodextrin solubilization of drugs. Int J Pharm 302: 18-28.

10. Loftsson T, Duchêne D (2007) Cyclodextrins and their pharmaceutical applications. Int J Pharm 329: 1-11.

11. Wu CY, Benet LZ (2005) Predicting drug disposition via application of BCS: transport/absorption/ elimination interplay and development of a biopharmaceutics drug disposition classification system. Pharm Res 22: 11-23.

12. Barone JA, Moskovitz BL, Guarnieri J, Hassell AE, Colaizzi JL, et al. (1998b) Food interaction and steady-state pharmacokinetics of itraconazole oral solution in healthy volunteers. Pharmacotherapy 18:295-301.

13. Barone JA, Koh JG, Bierman RH, Colaizzi JL, Swanson KA, et al. (1993) Food interaction and steady-state pharmacokinetics of itraconazole capsules in healthy male volunteers. Antimicrob Agents Chemother 37: 778-784.

14. Patterson TF, Peters J, Levine SM, Anzueto A, Bryan CL, et al. (1996) Systemic availability of itraconazole in lung transplantation. Antimicrob Agents Chemother 40: 2217-2220

15. Barone JA, Moskovitz BL, Guarnieri J, Hassell AE, Colaizzi JL, et al. (1998a) Enhanced bioavailability of itraconazole in hydroxypropyl-betacyclodextrin solution versus capsules in healthy volunteers. Antimicrob Agents Chemother 42:1862-1865.

16. Lahner E, Annibale B, Delle Fave G (2009) Systematic review: impaired drug absorption related to the co-administration of antisecretory therapy. Aliment Pharmacol Ther 29: 1219-1229.

17. Fotaki N, Klein S (2013) Mechanistic understanding of the effect of PPIs and acidic carbonated beverages on the oral absorption of itraconazole based on absorption modeling with appropriate in vitro data. Mol Pharm 10: 4016-4023

18. Zimmermann T, Yeates RA, Laufen H, Pfaff G, Wildfeuer A (1994) Influence of concomitant food intake on the oral absorption of two triazole antifungal agents, itraconazole and fluconazole. Eur J Clin Pharmacol 46: 147-150.

19. Yoo SD, Kang E, Jun H, Shin BS, Lee KC, et al. (2000) Absorption, firstpass metabolism, and disposition of itraconazole in rats. Chem Pharm Bull (Tokyo) 48: 798-801.

20. Shin JH, Choi KY, Kim YC, Lee MG (2004) Dose-dependent pharmacokinetics of itraconazole after intravenous or oral administration to rats: intestinal first-pass effect. Antimicrob Agents Chemother 48: 17561762.

21. Loftsson T, Brewster ME (2010) Pharmaceutical applications of cyclodextrins: basic science and product development. J Pharm Pharmacol 62: 1607-1621.

22. de Repentigny L, Ratelle J, Leclerc JM, Cornu G, Sokal EM, et al. (1998) Repeated-dose pharmacokinetics of an oral solution of itraconazole in infants and children. Antimicrob Agents Chemother 42: 404-408.

23. Yu LJ, Ma RD, Wang YQ, Nishino H, Takayasu J, et al. (1992) Potent antitumorigenic effect of tubeimoside 1 isolated from the bulb of Bolbostemma paniculatum (Maxim) Franquet. Int J Cancer 50: 635-638. 
Citation: Oda K, Umakoshi T, Mori N, Kasai R, Murakami T (2017) Biopharmaceutical Properties of Tubeimoside-1: A Cytotoxic Amphipathic Cyclic Bisdesmoside. Int J Clin Pharmacol Pharmacother 2: 126. doi: https://doi.org/10.15344/2017/2456-3501/126

Page 6 of 6

24. Yu L, Ma R, Wang Y, Nishino $\mathrm{H}$ (1994) Potent anti-tumor activity and low toxicity of tubeimoside 1 isolated from Bolbostemma paniculatum. Planta Med 60: 204-208.

25. Yu TX, Ma RD, Yu LJ (2001) Structure-activity relationship of tubeimosides in anti-inflammatory, antitumor, and antitumor-promoting effects. Acta Pharmacol Sin 22: 463-468.

26. Hao W, Wang S, Zhou Z (2015) Tubeimoside-1 (TBMS1) inhibits lung cancer cell growth and induces cells apoptosis through activation of MAPKJNK pathway. Int J Clin Exp Pathol 8: 12075-12083. 